Article

\title{
Performance Analysis and Working Fluid Selection for Single and Two Stages Vapor Compression Refrigeration Cycles
}

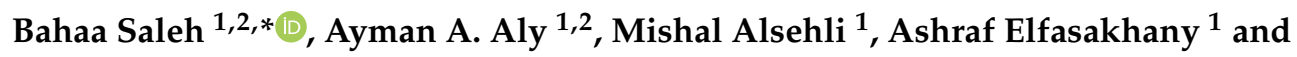 \\ Mohamed M. Bassuoni ${ }^{3}$ \\ 1 Mechanical Engineering Department, College of Engineering, Taif University, P.O. Box 888, Taif 26571, \\ Saudi Arabia; draymanelnaggar@tu.edu.sa (A.A.A.); m.alsehli@tu.edu.sa (M.A.); a.taha@tu.edu.sa (A.E.) \\ 2 Mechanical Engineering Department, Faculty of Engineering, Assiut University, Assiut 71516, Egypt \\ 3 Mechanical Power Engineering Department, Faculty of Engineering, Tanta University, Tanta 31733, Egypt; \\ bahaasaleh1969@gmail.com \\ * Correspondence: b.saleh@tu.edu.sa; Tel.: +966-055-6131-761
}

Received: 29 July 2020; Accepted: 11 August 2020; Published: 20 August 2020

check for updates

\begin{abstract}
Screening for alternative refrigerants with high energy efficiency and low environmental impacts is one of the highest challenges of the refrigeration sector. This paper investigates the performance and refrigerant screening for single and two stages vapor compression refrigeration cycles. Several pure hydrocarbons, hydrofluorocarbons, hydrofluoroolefins, fluorinated ethers, and binary azeotropic mixtures are proposed as alternative refrigerants to substitute R22 and R134a due to their environmental impacts. The BACKONE equation of state is used to compute the thermodynamic properties of the candidates. The results show that the maximum coefficients of performance (COP) for single and two stage cycles using pure substances are achieved using cyclopentane with values of 4.14 and 4.35 , respectively. On the other side, the maximum COP for the two cycles using azeotropic mixtures is accomplished using R134a + RE170 with values of 3.96 and 4.27 , respectively. The two-stage cycle presents gain in COP between $5.1 \%$ and $19.6 \%$ compared with the single-stage cycle based on the used refrigerant. From the obtained results, among all investigated refrigerants, cyclopentane is the most suitable refrigerant for the two cycles from the viewpoint of energy efficiency. However, extra cautions should be taken due to its flammability.
\end{abstract}

Keywords: refrigeration cycle; pure refrigerants; azeotropic mixtures; flash intercooler; cycle performance

\section{Introduction}

Currently, refrigeration systems are widely used in domestic and commercial applications. Approximately, there are three billion refrigeration systems used in the world which represent about $17 \%$ of the electrical power consumption over worldwide [1]. Accordingly, many researches have been conducted for improving the energy efficiency of these systems or to reduce their environmental effects. A minor enhancement in the system performance might have a significant effect on energy consumption.

The single-stage vapor compression refrigeration cycle (VCRC) is the most conventional refrigeration cycle. Many alternative refrigeration cycles were introduced to improve the cycle performance. These cycles may be different from the VCRC in their working principles such as the absorption cycle or might simply make changes in the cycle construction as the ejector, injection and cascade cycles. Alternative cycles tend to increase not only their energy efficiency but also initial costs and working complexity. Computational simulations permit to carry out a comparison between different alternative cycles in a cheap and fast way, introducing various options, assisting to decide if 
additional studies of some alternative cycles are worthwhile. Several studies have been conducted on alternative cycles to find the best energy-efficient cycle [1].

Many studies have reported that the vapor injection refrigeration cycle (VIRC) attains better performance than the VCRC. Heo et al. [2] carried out a comparison between a VCRC and VIRC. The study indicated that using vapor injection increases the cycle coefficient of performance (COP) by 25\%. Park et al. [3] and Xu et al. [4] presented the advantages of the flash tank with vapor injection compared with VCRC. Xu et al. [5] developed an integrated vapor injection heat pump system using R32, R1234yf, and its binary mixtures and evaluated their heating performances. The study concluded that the VIRC using R1234yf/R32 provided very significant performance enhancements for heating performance compared with no injection. Qi et al. [6] investigated a hybrid VIRC with subcooling and flash chamber for air-source heat pumps. The study concluded that the COP utilizing R290 was improved by about 3\% in comparison with the traditional subcooler VIRC. Tello-Oquendo et al. [7] offered a comprehensive study of the two-stage vapor compression refrigeration cycle (TSVCRC) using many refrigerants. Xu et al. [8] reported a new designed vapor injection heat pump utilizing R32. The study concluded that the heating COP was increased by nearly $13 \%$ in comparison with a cycle operates with liquid injection.

Many studies proposed mixtures as potential refrigerants for refrigeration systems [1,9]. Mohammad and Hoseyn [10] redesigned a TSVCRC by using the genetic algorithm and refrigerant analyses. The results showed that the basic redesign of the cycle, with propylene as refrigerant, improved the COP from 1.42 to 2.01 in comparison to the available cycle. $\mathrm{D}^{\prime}$ Angelo et al. [11] carried performance evaluation of a VIRC utilizing R290/R600a mixture. The maximum COP ( $\left.\mathrm{COP}_{\max }\right)$ was obtained using a mixture of $40 / 60 \mathrm{wt} \%$. The results showed that the COP of the VIRC was $16 \% \sim 32 \%$ higher than that of the VCRC. Lee et al. [12] measured a drop-in performance of R134a, R1234yf, and R1234yf/R134a mixture in a heat pump bench tester. The results showed that the COP of R1234yf and R1234yf/R134a is equal to that of R134a. Shaik and Babu [13] carried out a theoretical analysis of window air conditioner utilizing R410A, R431A, R134a, R290, R1270, R419A, and 15 mixtures. The results exhibited that the COP using the mixture R134a/R1270/R290 (50/5/45 mass\%) was 2.1\% higher than that of both the investigated pure and mixed refrigerants.

In the present study, a comparison between the performance of VCRC and TSVCRC using various traditional and new pure components and azeotropic and near azeotropic (almost no temperature glide) binary mixtures is conducted. The new pure and mixed refrigerants did not or seldom used in the previous studies. Using different expansion ratios, the performance of TSVCRC is calculated and optimized for $\mathrm{COP}_{\max }$. The refrigeration capacity, the compressor power, the compressor discharge temperature $\left(\mathrm{T}_{\mathrm{dis}}\right)$ and the COP are calculated and compared for the two cycles using all candidates. Fourteen pure components and sixteen mixtures are suggested and examined as refrigerants for VCRC and TSVCRC to substitute R22 and R134a due to their environmental impacts. The investigated pure refrigerants are cyclopentane, R1233zd(E), R1234yf, R1234ze(E), R604, R603, R602a, R602, R601a, R601, R600, R600a, R245ca, and RE170. The inspected mixtures are R290 + R143a, R125 + R290, R600a + R236fa, R227ea + R600a, R134a + R290, R134a + R600a, R152a + R600a, R125 + R143a (R507A), R32 + R125 (R410A), R32 + R290, R32 + R143a, RE170 + R600a, RE170 + R290, R22 + R115 (R502), R134a + RE170, and R1270 + R134a.

\section{Methodology}

\subsection{Single-Stage Vapor Compression Refrigeration Cycle Description}

Figure 1 shows a schematic diagram of the VCRC and its corresponding pressure-enthalpy (P-h) diagram. The cycle consists of a compressor, condenser, expansion valve and evaporator. There is no temperature glide for pure and azeotropic mixture refrigerants during condensation and evaporation processes. The different cycle processes can be explained as follows: process (1-4) is a compression through the compressor, process (4-5) is a heat rejection in the condenser, process (5-9) is an expansion 
through the expansion valve, process (9-1) is a heat addition in the evaporator. The arrangement of the numbers 1-4-5-9 is because of the ones used in the two-stage cycle as will be described in the next subsection.
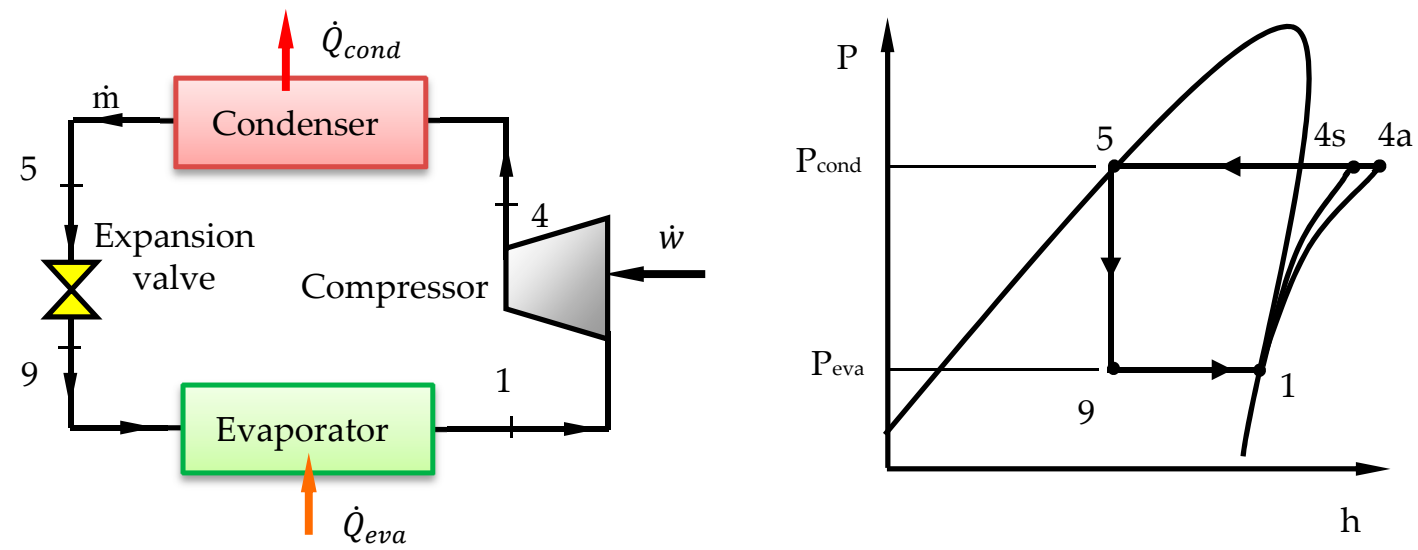

Figure 1. Schematic diagram of the VCRC and its P-h diagram.

\subsection{Two-Stage Compression Refrigeration Cycle with Flash Intercooler}

The COP of the refrigeration cycle can be increased by reducing the required compressor power. This can be achieved by multistage compression with intercooler. One arrangement for TSVCRC with flash intercooler and its corresponding P-h diagram are displayed in Figure 2. The TSVCRC differs from the VCRC by adding a second stage compression and a flash chamber which allows vapor injection between the two compression stages. Intercooling is accomplished by a direct contact heat exchanger. Saturated liquid refrigerant leaving the condenser at state 5 expands across the first expansion valve to the pressure of the flash chamber. The refrigerant enters the flash chamber as a liquid-vapor mixture at state 6 . In the flash chamber, the vapor and liquid components separate into two streams. Relatively low-temperature saturated vapor stream exits the flash chamber and enters the heat exchanger at state 7 , where it mixes with higher-temperature superheated refrigerant from the first stage compression at state 2 and the intercooling is achieved. A single stream leaves the heat exchanger at state 3 and is compressed by the second stage compressor to the condenser pressure at state 4 . Saturated liquid stream leaving the flash chamber at state 8 expands across the second expansion valve to the evaporator pressure reaching the lowest temperature in the cycle, where it picks up heat from the refrigerated space. The refrigerant exits from the evaporator as saturated vapor at state 1 and enters the first stage compressor.

\subsection{Refrigerant Selection}

The ideal refrigerant achieves both high system performance and minimal environmental impacts. The refrigerant should have high latent heat of vaporization, promising heat transfer properties, and a wide operating temperature range [14]. The following general concerns are addressed during the refrigerant choice: (i) environmental impacts: global warming potential (GWP), ozone depletion potential (ODP), and atmospheric lifetime (ALT); (ii) safety features: flammability, auto ignition, and toxicity; and (iii) availability and cost.

A significant feature for the refrigerant classification is the shape of the saturated vapor line in the temperature against the entropy (T-s) diagram. The saturated vapor line may lead to three refrigerant types, i.e., (i) overhanging, if the saturated vapor line forms a positive slope. For overhanging refrigerants, the state after the compressor may be in the two-phase region, which is called wet compression. This may seriously influence the gas-dynamic process in the compressor and hence the compressor performance. In practice, wet compression can be averted by non-isentropic compression and if needful greater superheating before the compressor inlet; (ii) a bell-shaped coexistence curve, 
if the saturated vapor line constitutes a negative slope; and (iii) isentropic, if the saturated vapor line is almost vertical. For both bell-shaped and isentropic refrigerants, there is no phase change during the compression process and the superheating before the compressor is not required. The notations $0, b$, and $\mathrm{i}$ are used hereafter for overhanging, bell-shaped, and isentropic refrigerants, respectively.
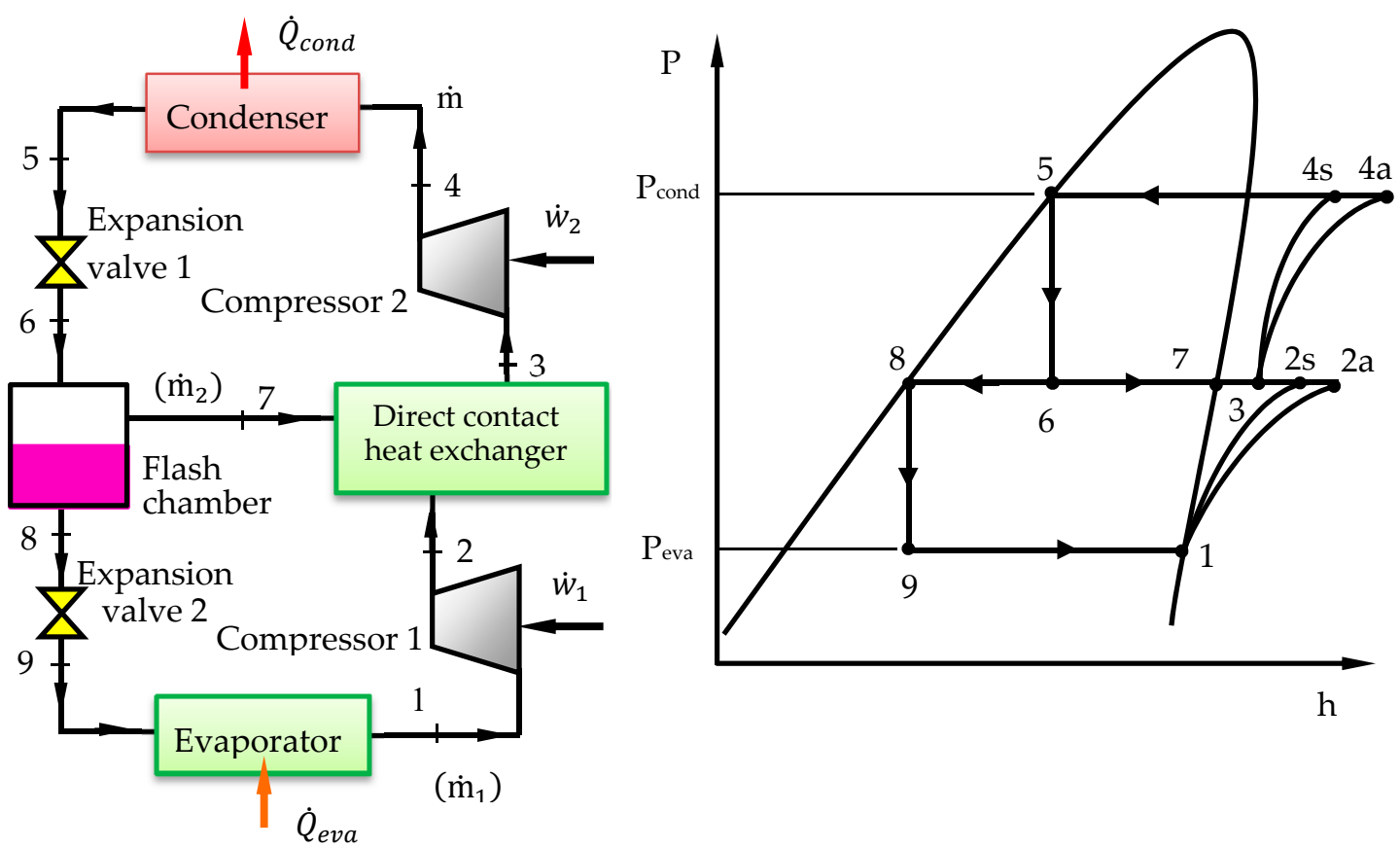

Figure 2. Schematic diagram of the TSVCRC and its P-h diagram.

For several years, chlorofluorocarbons (CFCs) and hydrochlorofluorocarbons (HCFCs) have been used as refrigerants. In 1987, the Montreal Protocol was ratified and the use of CFCs and HCFCs was regulated. Consequently, they have been phased out due to their ODP and high GWP. This forced researchers to use hydrofluorocarbons (HFCs) as alternative refrigerants. The HFCs have zero ODP and have several of the promising properties. They have considerable features regarding stability, low toxicity, and safety, being suitable for large-scale refrigeration systems [15]. The regulations are becoming stricter in terms of environment protection; accordingly, using HFCs are now being regulated due to their large GWP.

Nowadays, the emphasis is on the utilization of natural refrigerants, such as hydrocarbons (HCs). The HCs have zero ODP, very small GWP, and superior thermophysical properties. They are highly soluble in traditional mineral oils, non-toxic, chemically stable, compatible with conventional materials used in the refrigeration systems [16]. However, the HCs are highly flammable, which limits their utilization [17]. Hydrofluoroolefins (HFOs) are considered promising alternative refrigerants because they are ozone-friendly. They can offer a balance among performance, durability, environmental effect, and safety [15]. Several HFOs are used as alternative refrigerants [18,19]. Both azeotropic and zeotropic mixtures have been examined as refrigerants in the literature. The azeotropic mixtures are catching increasing interest in refrigeration applications because of their zero temperature glide and particular thermophysical properties [9].

The fundamental thermodynamic properties of the inspected refrigerants such as molecular mass $(\mathrm{M})$, normal boiling point $(\mathrm{NBP})$, critical volume $\left(\mathrm{v}_{\mathrm{c}}\right)$, critical temperature $\left(\mathrm{T}_{\mathrm{c}}\right)$, and critical pressure $\left(\mathrm{P}_{\mathrm{c}}\right)$ are presented in Table $1[20,21]$. Also, the environmental and safety (lower flammability limit, $\%$ by volume in the air (LFL), and safety group) features are presented in Table 1. 
Table 1. Properties of the pure substances [20,21].

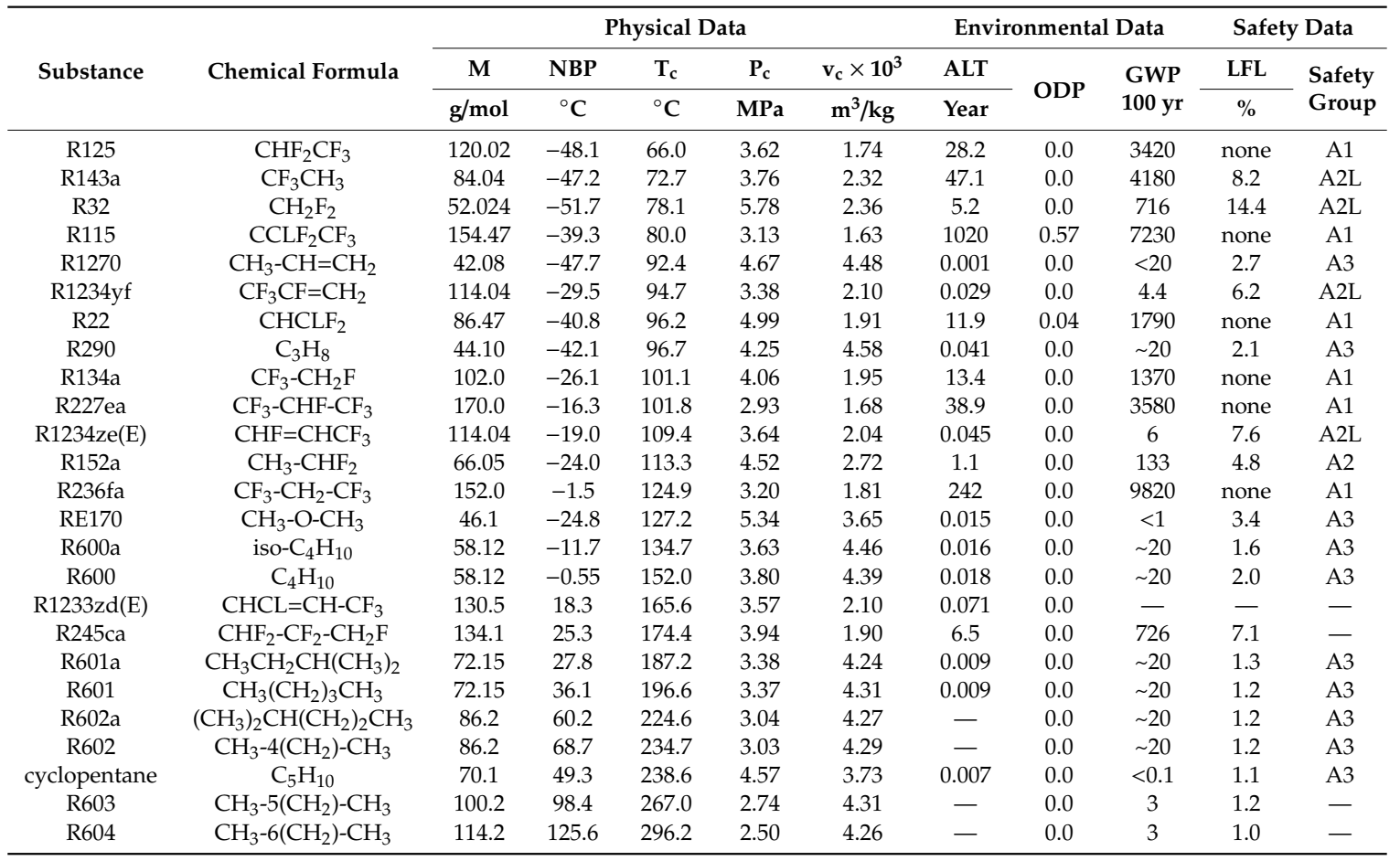

\section{Mathematical Model}

\subsection{VCRC Mathematical Model}

The mathematical thermodynamic model for the VCRC can be described as follows:

$$
\dot{W}_{c o m p, a}=\dot{m}\left(h_{4 a}-h_{1}\right)=\frac{\dot{W}_{c o m p, s}}{\eta_{c o m p}}=\frac{\dot{m}\left(h_{4 s}-h_{1}\right)}{\eta_{c o m p}}
$$

where $\dot{W}_{c o m p, a}$ and $\dot{W}_{c o m p, s}$ are the actual and isentropic compressor power, respectively, $\eta_{\text {comp }}$ is the compressor isentropic efficiency, $\dot{m}$ is the refrigerant mass flow rate, and $h$ is the specific enthalpy indicated in the subscript.

$$
\dot{\mathrm{Q}}_{\mathrm{eva}}=\dot{m}\left(h_{1}-h_{9}\right)
$$

where $\dot{\mathrm{Q}}_{\mathrm{eva}}$ is the refrigeration capacity.

$$
\begin{aligned}
\mathrm{COP}_{\mathrm{VCRC}} & =\frac{\dot{\mathrm{Q}}_{\mathrm{eva}}}{\dot{\mathrm{W}}_{\text {comp }, a}} \\
\mathrm{CCR} & =\frac{P_{4}}{P_{1}}
\end{aligned}
$$

where CCR is the compressor compression ratio, and $P_{1}$ and $P_{4}$ are the pressure at the compressor inlet and outlet, respectively.

\subsection{TSVCRC Mathematical Model}

The mathematical model for the TSVCRC is described as follows:

$$
\mathrm{ER}=\frac{P_{5}-P_{6}}{P_{5}}
$$


where ER is the expansion ratio in the upper sub-cycle expansion valve, and $P_{5}$ and $P_{6}$ are the pressures at the expansion valve inlet and outlet, respectively.

The refrigerant two streams mass flow rate outlet from the flash chamber can be calculated by applying the mass and energy conservation principles as follows:

$$
\begin{gathered}
\dot{m}=\dot{m}_{1}+\dot{m}_{2} \\
\dot{m} h_{6}=\dot{m}_{1} h_{8}+\dot{m}_{2} h_{7}
\end{gathered}
$$

where $\dot{m}$ is the total mass flow rate in the upper sub-cycle, and $\dot{m}_{1}$ and $\dot{m}_{2}$ are the vapor and liquid mass flow rates exit from the flash chamber.

The specific enthalpy at the heat exchanger outlet $\left(h_{3}\right)$ can be found by applying energy balance to the heat exchanger:

$$
\begin{gathered}
h_{3}=\frac{\dot{m}_{1} h_{2}+\dot{m}_{2} h_{7}}{\dot{m}} \\
\dot{W}_{c o m p 1, a}=\dot{m}_{1}\left(h_{2 a}-h_{1}\right)=\frac{\dot{W}_{c o m p 1, s}}{\eta_{c o m p 1}}=\frac{\dot{m}_{1}\left(h_{2 s}-h_{1}\right)}{\eta_{c o m p 1}} \\
\dot{W}_{c o m p 2, a}=\dot{m}\left(h_{4 a}-h_{3}\right)=\frac{\dot{W}_{c o m p 2, s}}{\eta_{c o m p 2}}=\frac{\dot{m}\left(h_{4 s}-h_{3}\right)}{\eta_{c o m p 2}} \\
\dot{W}=\dot{W}_{c o m p 1, a}+\dot{W}_{c o m p 2, a} \\
\dot{\mathrm{Q}}_{\text {eva }}=\dot{m}_{1}\left(h_{1}-h_{9}\right) \\
\operatorname{COP}_{\mathrm{TSVCRC}}=\frac{\dot{\mathrm{Q}}_{\mathrm{eva}}}{\dot{W}}
\end{gathered}
$$

\section{Results and Discussion}

\subsection{Thermodynamic Data}

The BACKONE equations are a family of physically-based equations of state which are able to describe thermodynamic properties of nonpolar, dipolar and quadrupolar fluids with a very good accuracy. The BACKONE equations yield accurate thermodynamic properties of pure as well as mixed refrigerants. Because of their high predictive power the BACKONE equations are a reliable tool for the application to many different pure and mixed refrigerants, especially if there is a lack of reliable data. The thermodynamic properties of many pure working fluids were described precisely by BACKONE [22-27]. Also, the thermodynamic properties of binary mixtures were described accurately with BACKONE [27-29]. One binary interaction parameter $\left(k_{12}\right)$ was fitted for each binary system only to binary vapor-liquid equilibrium (VLE) data. None of the previous studies which studied the TSVCRC with intermediate intercooler and flash tank used BACKONE to calculate the refrigerants thermodynamic properties. In the present study, the thermodynamic properties of the investigated pure and mixed refrigerants are computed by the BACKONE equation of state. Table 2 gives an overview of the investigated mixtures and their phase behavior, where $x_{1}$ denotes the concentration at azeotrope [29]. A computer program is developed to evaluate and compare the VCRC and TSVCRC performances using all candidates under various operating conditions.

Some results for binary VLE data calculated by BACKONE are displayed in Figure 3 [23]. The mixtures are divided into two categories, i.e., negative azeotrope and positive azeotrope. $\mathrm{R} 134 \mathrm{a}+\mathrm{RE} 170$ is an example of a distinctive negative azeotropic mixture as shown in Figure 3a. An azeotropic mixture at approximately 30 mole \% R134a would be very suitable for an application as a refrigerant. R134a + R600a is an example of a typical positive azeotropic mixture as shown in Figure 3b. The azeotrope is at nearly 72 mole \% R134a. The negative and positive azeotropes are depending on 
negative or positive deviations from Raoult's law. The mixtures of ethers with HFCs have typically negative deviation from Raoult's law, while RE170 with the R290 or R600a show positive deviation from Raoult's law. The negative deviation is attributing to the hydrogen bonding of the ethers. The physical background of BACKONE does not allow hydrogen bonding. However, the different deviations from Raoult's law are refracted in the parameter $k_{12}$. Negative $k_{12}$ yields negative deviations; positive $k_{12}$ yields positive deviations from Raoult's law. R125 + R143a is the only mixture without ether which displays a negative deviation from Raoult and it has a negative $\mathrm{k}_{12}$.

\subsection{Performance Analysis of VCRC}

A comparison between the performance of the VCRC using various pure and mixed alternative refrigerants is conducted. Fourteen pure components and sixteen mixtures are examined as alternative refrigerants in VCRC. The evaporator and condenser temperatures are fixed at $-10{ }^{\circ} \mathrm{C}$ and $35{ }^{\circ} \mathrm{C}$, respectively. The compressor efficiency is kept constant at $80 \%$. The refrigerant mass flow rate is fixed at $1 \mathrm{~kg} / \mathrm{s}$. The $\dot{W}, \dot{\mathrm{Q}}_{\mathrm{eva}}, \mathrm{COP}, \mathrm{T}_{\mathrm{dis}}$, and CCR are calculated and compared for each candidate.

Table 2. VLE of the investigated mixtures calculated by BACKONE.

\begin{tabular}{cccc}
\hline Mixture & Phase Behavior & $\boldsymbol{x}_{\mathbf{1}}$ & $\mathbf{k}_{\mathbf{1 2}}$ \\
\hline R290 + R143a & azeotropic & 0.35 & 0.077 \\
R125 + R290 & azeotropic & 0.65 & 0.083 \\
R600a + R236fa & azeotropic & 0.56 & 0.081 \\
R227ea + R600a & azeotropic & 0.63 & 0.072 \\
R134a + R290 & azeotropic & 0.40 & 0.073 \\
R134a + R600a & azeotropic & 0.71 & 0.073 \\
R152a + R600a & azeotropic & 0.74 & 0.071 \\
R125 + R143a & near azeotropic & $0.0: 1.0$ & -0.032 \\
R32 + R125 & near azeotropic & $<0.19,>0.69$ & 0.006 \\
R32 + R290 & azeotropic & 0.68 & 0.033 \\
R32 + R143a & near azeotropic & 0.85 & 0.003 \\
RE170 + R600a & azeotropic & 0.90 & 0.026 \\
RE170 + R290 & azeotropic & 0.1 & 0.028 \\
R22 + R115 & azeotropic & 0.63 & 0.044 \\
R134a + RE170 & azeotropic & 0.30 & -0.034 \\
R1270 + R134a & azeotropic & 0.81 & 0.051 \\
\hline
\end{tabular}


Figure 3. Pressure-concentration diagrams for; negative azeotrope (a), and positive azeotrope (b).

Table 3 lists the results of $\dot{W}, \dot{\mathrm{Q}}_{\mathrm{eva}}, \mathrm{COP}, \mathrm{T}_{\mathrm{dis}}$, and CCR for the VCRC using the investigated pure refrigerants besides the refrigerant type. Cyclopentane accomplishes the uppermost $\dot{Q}_{\text {eva }}$ of $351.2 \mathrm{~kW}$. Cyclopentane and RE170 exhibited higher $\dot{W}$ than R22 and R134a, but their higher $\dot{Q}_{\text {eva }}$ will compensate for this. 
While examining alternative refrigerants the lifespan, compressor motor durability, and system consistency should be investigated. These parameters can be inspected by computing $T_{\text {dis }}$. The $T_{\text {dis }}$ depends on refrigerant and system pressure, and it must be controlled to avert oil properties deterioration or even burnout the oil. High $\mathrm{T}_{\text {dis }}$ is harmful to the system performance and indicates high stress on the compressor and hence a shorter compressor life [30,31]. Table 3 shows that R22 achieves the highest $\mathrm{T}_{\text {dis. }}$. Thus, it indicates longer compressor life when using any inspected alternative refrigerant compared to $\mathrm{R} 22$. The $\mathrm{T}_{\text {dis }}$ for all investigated pure refrigerants is reduced by $4.21^{\circ} \mathrm{C}$ to $31.66{ }^{\circ} \mathrm{C}$ compared to $\mathrm{R} 22$.

Table 3. Results for VCRC using investigated pure refrigerants.

\begin{tabular}{ccccccc}
\hline Refrigerant & Type & $\dot{\mathbf{W}}, \mathbf{k W}$ & $\dot{\mathbf{Q}}_{\mathbf{e v a}}, \mathbf{k W}$ & $\mathbf{C O P}$ & $\mathbf{T}_{\text {dis }}{ }^{\circ} \mathbf{C}$ & $\mathbf{C C R}$ \\
\hline cyclopentane & o & 84.8 & 351.2 & 4.14 & 62.48 & 7.20 \\
R1233zd(E) & i & 39.5 & 154.4 & 3.91 & 43.79 & 6.08 \\
R1234yf & i & 31.1 & 109.1 & 3.51 & 37.92 & 4.04 \\
R1234ze(E) & i & 35.2 & 129.4 & 3.68 & 40.47 & 4.53 \\
R22 & b & 42.0 & 158.1 & 3.77 & 66.69 & 3.82 \\
R604 & o & 72.7 & 287.4 & 3.96 & 35.83 & 17.25 \\
R603 & o & 72.8 & 288.0 & 3.96 & 36.10 & 12.31 \\
R602a & o & 69.3 & 271.4 & 3.92 & 35.02 & 7.99 \\
R602 & o & 73.1 & 288.7 & 3.95 & 36.68 & 8.82 \\
R601a & o & 69.6 & 270.9 & 3.90 & 36.61 & 5.87 \\
R601 & o & 73.8 & 290.0 & 3.93 & 38.03 & 6.43 \\
R600 & o & 74.2 & 286.9 & 3.87 & 40.37 & 4.72 \\
R600a & o & 68.0 & 257.3 & 3.78 & 39.11 & 4.29 \\
R134a & b & 38.7 & 143.7 & 3.72 & 48.24 & 4.42 \\
R245ca & o & 41.8 & 162.5 & 3.89 & 41.00 & 7.05 \\
RE170 & b & 86.9 & 340.3 & 3.92 & 58.89 & 4.21 \\
\hline
\end{tabular}

Figure 4 displays the COP of the VCRC using all examined pure candidates. Cyclopentane accomplishes the topmost COP of 4.14, while R1234yf attains the lowermost COP of 3.51. R22 and R134a achieve COP of 3.77 and 3.71, respectively. Cyclopentane achieves the best cycle performance and seems to be the best replacement for R22 and R134a. The COP of cyclopentane is $9.9 \%$ and $11.5 \%$ greater than those of R22 and R134a, respectively.

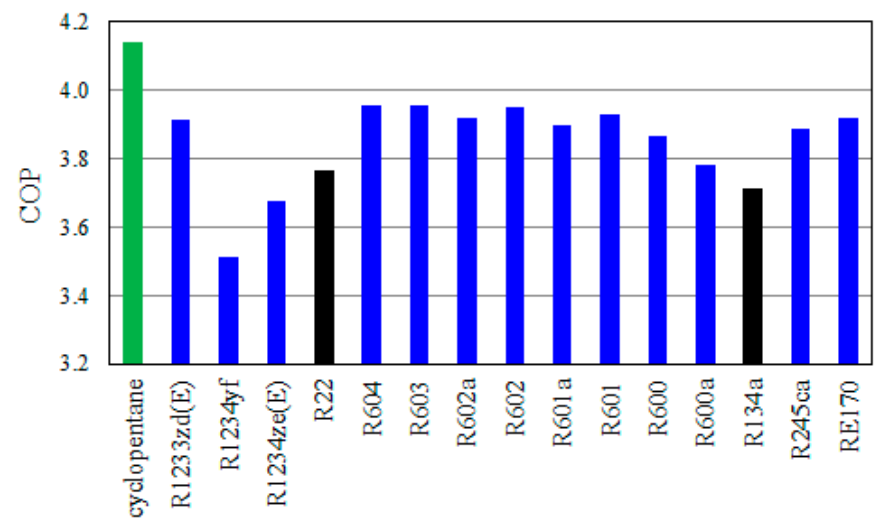

Figure 4. The COP of VCRC using pure refrigerants.

The CCR is a measure for the required compressor size. Accordingly, to use an alternative refrigerant as a replacement refrigerant in an existing system without changing the compressor, its CCR should be similar to that of the existing refrigerant. Figure 5 shows the COP and CCR values using pure refrigerants relative to reference refrigerants R22 and R134a. Figure 5a shows the COP and CCR values relative to $\mathrm{R} 22$. It can be detected that most of the examined pure refrigerants (12 refrigerant) 
have a higher COP than R22. R134a and R1234ze(E) have COP values a little lower than that of R22 while they have CCR values very close to that of R22. R600, R600a, and RE170 have COP values a little higher than that of R22 while having CCR very close to that of R22. Cyclopentane has the highest COP and its CCR is nearly 1.9 times that of R22.
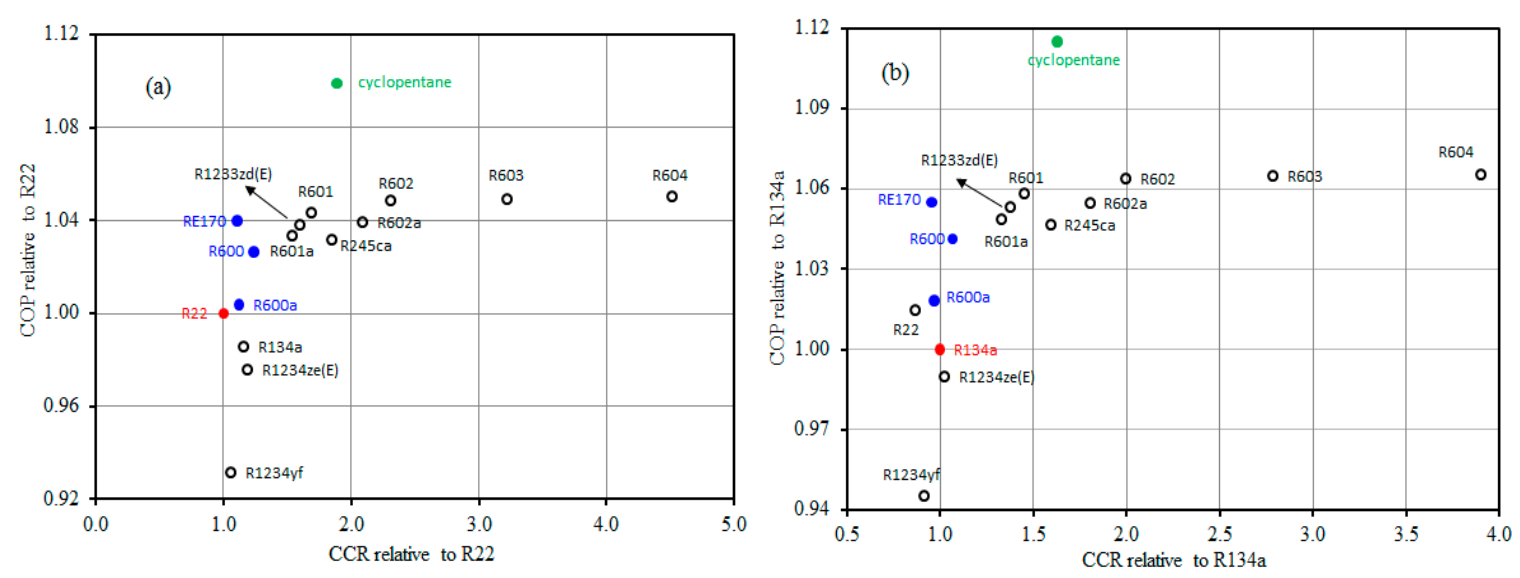

Figure 5. Comparison of the COP and CCR of pure alternative refrigerants relative to R22 (a) and R134a (b).

Figure 5b displays the COP and CCR values relative to R134a. R600a, R600, and RE170 have COP values higher than that of R134a besides they have CCR values very close to that of R134a. R1234ze(E) has a similar CCR with that of R134a while achieves a lower COP. Cyclopentane has a much higher COP than that of R134a and its CCR 1.6 times that of R134a. From Figure 5, if it is desired to replace R22 or R134a in the already existing systems, RE170 may be considered the best alternative because it has the same CCR as R22 and R134a while it has a higher COP. For new systems, cyclopentane may consider as the best refrigerant to substitute R22 and R134a. Cyclopentane has zero ODP and very low GWP, appropriate to widespread materials used in refrigeration systems and soluble in common mineral oils. The most worry regarding the adoption of cyclopentane as a replacement for R22 and R134a is its flammability. It should be noticed that a huge amount of HCs are utilized safely each year all over the world for heating, cooking, aerosol propellants and powering vehicles. In such industries, procedures and standards have been established and adopted for safety. A similar approach is followed in the refrigeration industry as well.

Table 4 lists the results of $\dot{W}, \dot{Q}_{\text {eva }}$, COP, $\mathrm{T}_{\text {dis }}$, and CCR for the VCRC using the investigated mixtures. R134a + RE170 and RE170 + R600a accomplish the topmost COP values of 3.96 and 3.94, respectively. The COP of R134a + RE170 is $5.0 \%$ and $6.6 \%$ higher than those of R22 and R134a, respectively. The two mixtures achieve approximately the same $\mathrm{T}_{\text {dis }}$ which is lower than that of R22 by $11.5^{\circ} \mathrm{C}$ and higher than that of R134a by about $7.1{ }^{\circ} \mathrm{C}$. R125 + R290 achieves the lowermost COP of 3.06.

Figure $6 \mathrm{a}, \mathrm{b}$ display the COP and CCR values using all investigated mixtures relative to $\mathrm{R} 22$ and R134a. It can be detected from Figure 6a that most of the examined mixtures (14 mixtures) have a lower COP than R22. R152a + R600a and R22 have a similar COP and their CCR matches very well. The CCRs of both mixtures RE170 + R600a and R134a + RE170 are a little higher than that of R22, but they accomplish the highest COP. It can be observed from Figure $6 \mathrm{~b}$ that most of the investigated mixtures (13 mixtures) have a lower COP than that of R134a. The COP and CCR attained by R600a + R236fa are approximately the same as those accomplished by R134a. The CCRs of RE170 + R600a and R134a + RE170 match very well with that of R134a while accomplishing the highest COP value. Accordingly, the two azeotropic mixtures RE170 + R600a and R134a + RE170 can be considered as promising alternatives for R22 and R134a. 


\subsection{Performance Analysis of TSVCRC}

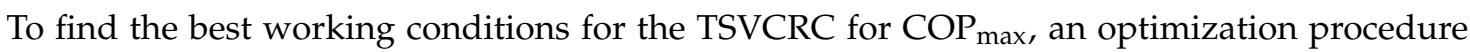
was carried out to find the best ER. The procedure used in the optimization process is as follows. The condenser and evaporator temperatures were kept constant at $35^{\circ} \mathrm{C},-10^{\circ} \mathrm{C}$, respectively. The two compressors isentropic efficiencies were kept constant at $80 \%$. The refrigerant mass flow rate in the second compressor, condenser, and the first expansion valve was fixed at $1 \mathrm{~kg} / \mathrm{s}$. According to ER, the mass flow in the second expansion valve, evaporator, and the first compressor was calculated. The $\dot{W}, \dot{Q}_{\text {eva }}$, and the COP were calculated and compared for each ER. The ER achieves the COP $\max$ was considered as optimum ER. The ER was examined in the range between 0.2 and 0.8 . This range is selected because lower ER values make TSVCRC tends to VCRC, while higher ones are not practicable. This procedure was followed for all candidates. A comparison between the performance of TSVCRC using all candidates is conducted. The $\dot{W}, \dot{Q}_{\text {eva }}$, and COP are calculated and compared for each candidate.

Table 4. Results for VCRC using investigated mixtures.

\begin{tabular}{|c|c|c|c|c|c|}
\hline Mixture & $\dot{W}, \mathbf{k W}$ & $\dot{\mathrm{Q}}_{\mathrm{eva}}, \mathrm{kW}$ & COP & $\mathrm{T}_{\text {dis }},{ }^{\circ} \mathrm{C}$ & CCR \\
\hline $\mathrm{R} 290+\mathrm{R} 143 \mathrm{a}$ & 42.3 & 138.6 & 3.28 & 49.66 & 3.40 \\
\hline $\mathrm{R} 125$ + R290 & 30.9 & 94.5 & 3.06 & 45.26 & 3.42 \\
\hline R600a + R236fa & 41.9 & 155.2 & 3.70 & 44.86 & 4.44 \\
\hline R227ea + R600a & 29.1 & 99.2 & 3.40 & 36.63 & 4.16 \\
\hline $\mathrm{R} 134 \mathrm{a}+\mathrm{R} 290$ & 54.0 & 181.7 & 3.37 & 38.66 & 3.52 \\
\hline $\mathrm{R} 134 \mathrm{a}+\mathrm{R} 600 \mathrm{a}$ & 41.3 & 148.4 & 3.60 & 47.72 & 4.05 \\
\hline $\mathrm{R} 152 \mathrm{a}+\mathrm{R} 600 \mathrm{a}$ & 59.8 & 225.2 & 3.76 & 53.03 & 4.12 \\
\hline $\mathrm{R} 125$ + R143a & 31.6 & 104.6 & 3.31 & 44.67 & 3.68 \\
\hline $\mathrm{R} 32$ + R125 & 46.6 & 166.0 & 3.56 & 67.98 & 3.73 \\
\hline $\mathrm{R} 32+\mathrm{R} 290$ & 60.7 & 203.7 & 3.35 & 65.81 & 3.38 \\
\hline $\mathrm{R} 32+\mathrm{R} 143 \mathrm{a}$ & 59.8 & 217.1 & 3.63 & 74.86 & 3.71 \\
\hline RE170 + R600a & 82.5 & 325.2 & 3.94 & 55.11 & 4.18 \\
\hline RE170 + R290 & 74.1 & 273.6 & 3.69 & 48.95 & 3.55 \\
\hline $\mathrm{R} 22+\mathrm{R} 115$ & 28.6 & 99.8 & 3.49 & 45.41 & 3.60 \\
\hline R134a + RE170 & 63.2 & 250.0 & 3.96 & 55.29 & 4.33 \\
\hline $\mathrm{R} 1270$ + R134a & 59.7 & 216.5 & 3.63 & 53.20 & 3.49 \\
\hline
\end{tabular}
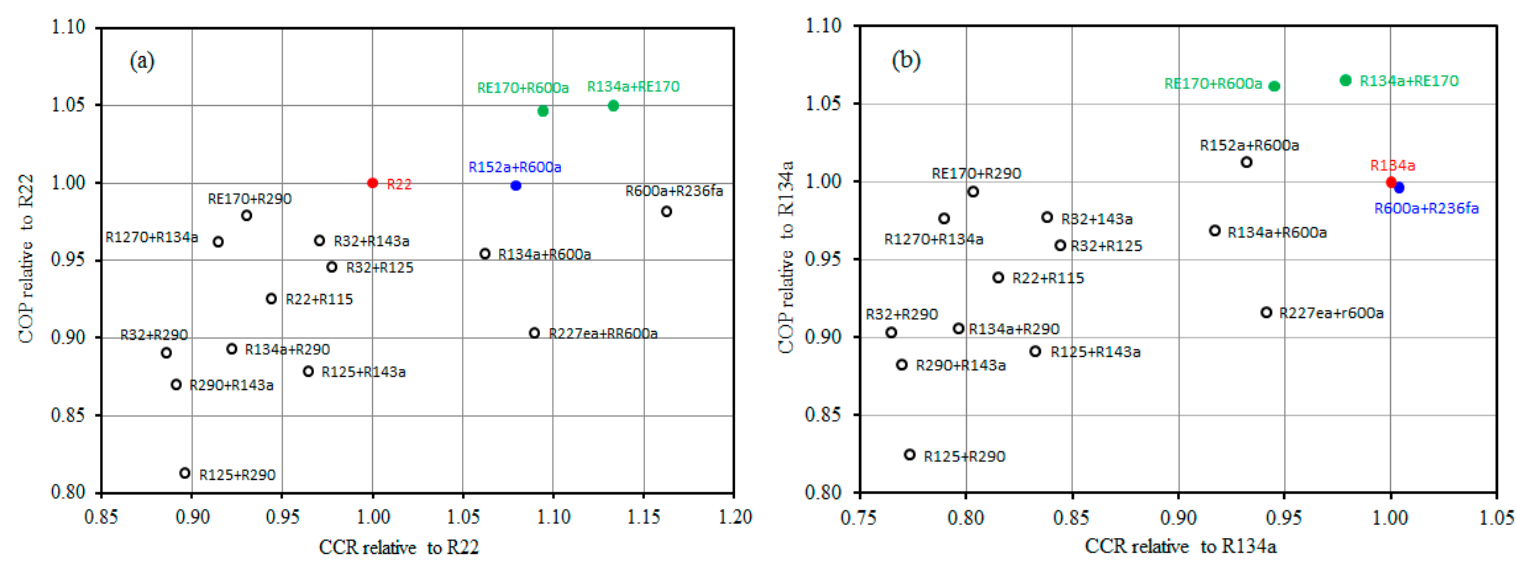

Figure 6. Comparison of the COP and CCR of the inspected mixtures relative to R22 (a) and R134a (b).

The variations of COP of the TSVCRC with ER using all inspected pure and mixed refrigerants are presented in Figure 7a,b, respectively. Generally, for both pure and mixed refrigerants, the COP increases with the increase of ER until a maximum value then decreases with the continuous increase of ER. Among all investigated pure refrigerants as can be detected from Figure $7 \mathrm{a}$, cyclopentane accomplishes 
the highest COP for all examined ER. With respect to mixtures as shown in Figure 7b, R134a + RE170 accomplishes the highest COP for all examined ER.

Figure 8 displays the $\mathrm{COP}_{\max }$ of the TSVCRC using pure and mixed refrigerants. As shown in Figure $8 \mathrm{a}$, cyclopentane achieves the highest $\mathrm{COP}_{\max }$. The $\mathrm{COP}_{\max }$ using cyclopentane is 4.35 at an ER of 0.6 which is higher than those of R22 and R134a by about $6.9 \%$ and $5.8 \%$, respectively. As shown in Figure 8b, R134a + RE170, and RE170 + R600a accomplish the highest COP $\max$. The COP max $_{\text {axing }}$ R134a + RE170, and RE170 + R600a are 4.27 and 4.25, respectively at an ER of 0.5. The COP $\max$ using $\mathrm{R} 134 \mathrm{a}+\mathrm{RE} 170$ is higher than those of R22 and R134a by about $4.98 \%$ and $3.86 \%$, respectively.

The COP of the VCRC and TSVCRC using cyclopentane is $4.15,4.35$, respectively. The gain in COP of the TSVCRC using cyclopentane compared with that of VCRC is approximately $5.1 \%$. On the other side, the COP of the VCRC and TSVCRC using R134a + RE170 is 3.96, 4.27, respectively. The gain in COP of TSVCRC using R134a + RE170 compared with that of VCRC is nearly $7.96 \%$. The TSVCRC presented a gain in COP between $5.1 \%$ and $19.6 \%$ compared with the VCRC based on the refrigerant type.
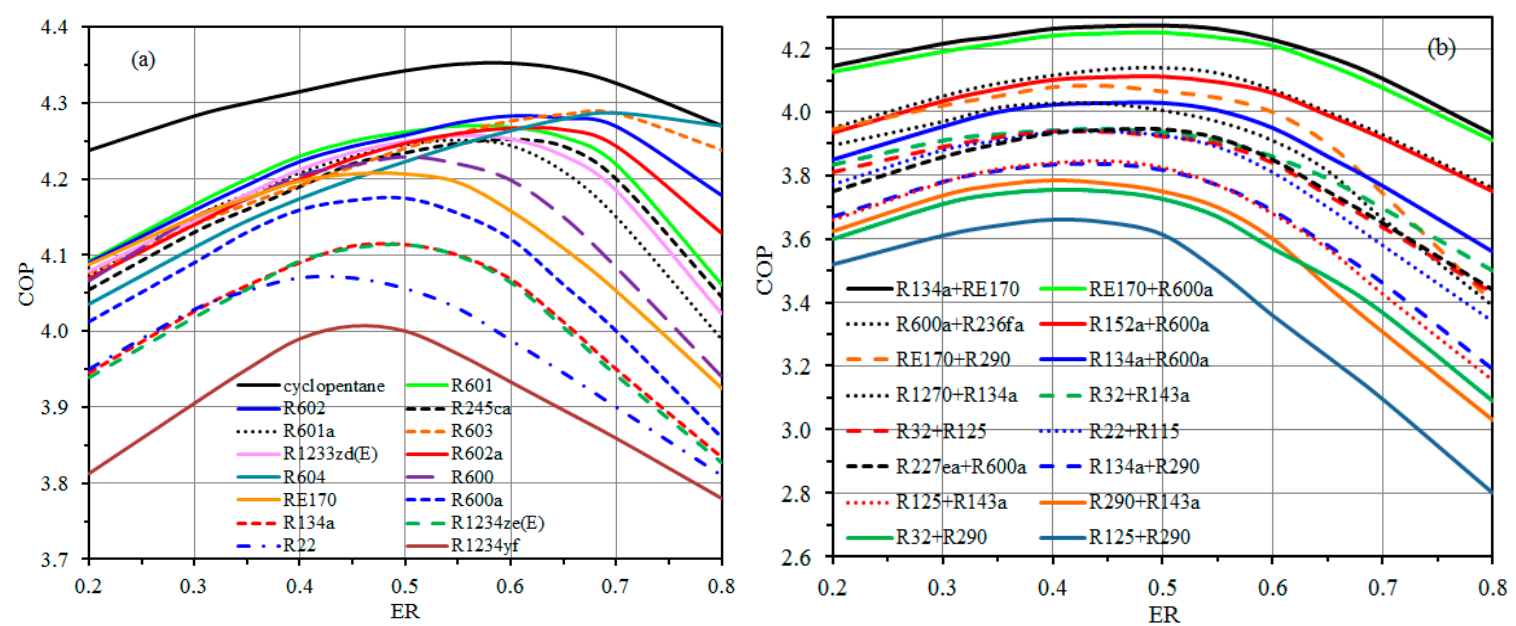

Figure 7. Effect of ER on COP of the TSVCRC using; pure refrigerants (a), and mixed refrigerants (b).
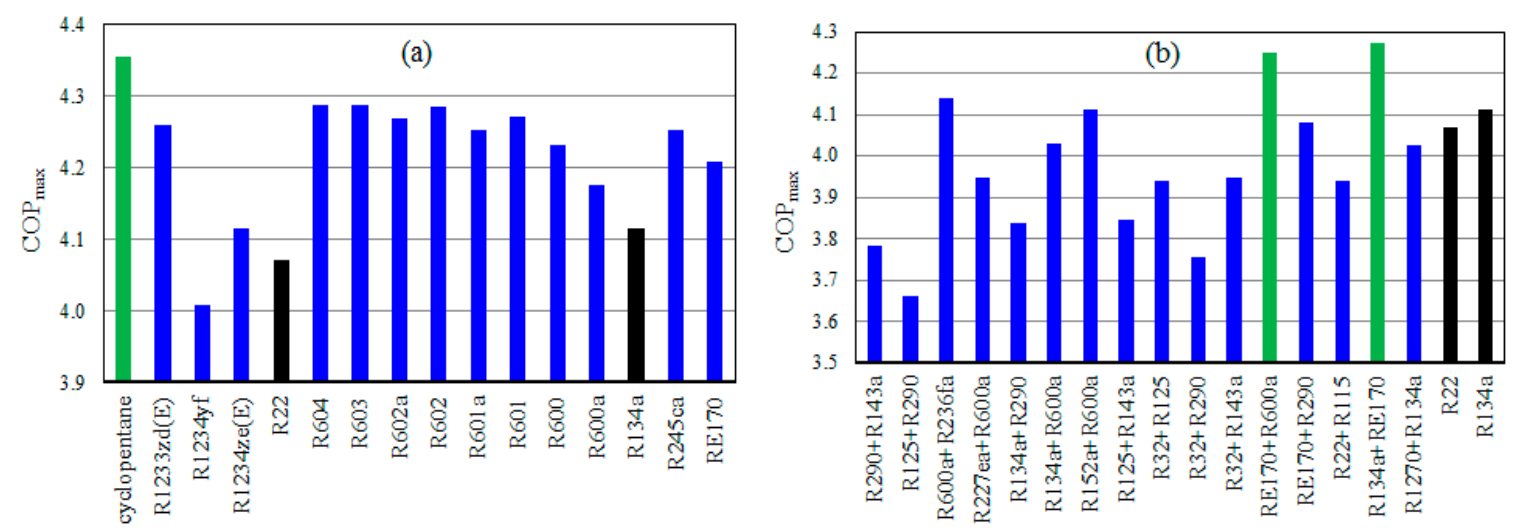

Figure 8. The $\mathrm{COP}_{\max }$ of TSVCRC using pure refrigerants (a), and mixed refrigerants (b).

\section{Conclusions}

In the present study, performance comparison and refrigerant screening for single and two stages vapor compression refrigeration cycle are conducted. Many pure and mixed refrigerants were proposed to substitute R22 and R134a. Using various expansion ratios, the performance of the two-stage cycle was calculated and optimized for maximum COP.

The results show that the highest COP for single and two stages cycles using pure refrigerants are accomplished by cyclopentane with values 4.14 and 4.35 , respectively. The COP of the two-stage 
cycle is greater than that of the single-stage cycle by about $5.1 \%$ using cyclopentane. The compressor compression ratio of cyclopentane matches well with those of R22 and R134a. On the other side, the maximum COP for single and two stages cycles using azeotropic mixtures are attained by $\mathrm{R} 134 \mathrm{a}+\mathrm{RE} 170$ with values 3.96 and 4.27, respectively. The gain in COP of the two-stage cycle using $\mathrm{R} 134 \mathrm{a}+\mathrm{RE} 170$ compared with that of the single-stage cycle is $7.96 \%$. From the obtained results it can be concluded that, among the investigated pure and azeotropic refrigerants, cyclopentane is the most appropriate alternative for R22 and R134a for both cycles from the perspective of energy efficiency. However, its flammability needs extra precautions to be considered. As future work, an experimental test rig will be built to validate this theoretical study.

Author Contributions: Conceptualization, B.S.; data curation, A.A.A.; formal analysis, B.S.; funding acquisition, B.S.; investigation, B.S.; methodology, B.S.; project administration, B.S.; resources, M.M.B.; software, B.S.; supervision, B.S.; validation, B.S.; visualization, A.E.; writing—original draft, M.A.; writing-review \& editing, B.S. All authors have read and agreed to the published version of the manuscript.

Funding: This research was funded by Taif University under research grant number 1-439-6073.

Acknowledgments: This study is supported by Taif University under research grant 1-439-6073. The authors would like to thank Taif University for the financial support.

Conflicts of Interest: The authors declare no conflict of interest.

\section{References}

1. Carvalho, S.M.R.; Massuchetto, L.H.P.; Nascimento, R.B.C.; Araujo, H.V.; D'Angelo, J.V.H. Optimization of a vapor injection refrigeration cycle using hydrocarbon mixed refrigerants. Int. J. Refrig. 2019, 98, 109-119. [CrossRef]

2. Heo, J.; Jeong, M.W.; Kim, Y. Effects of flash tank vapor injection on the heating performance of an inverter-driven heat pump for cold regions. Int. J. Refrig. 2010, 33, 848-855. [CrossRef]

3. Park, C.; Lee, H.; Hwang, Y.; Radermacher, R. Recent advances in vapor compression cycle technologies. Int. J. Refrig. 2015, 60, 118-134. [CrossRef]

4. Xu, X.; Hwang, Y.; Radermacher, R. Refrigerant injection for heat pumping/air conditioning systems: Literature review and challenges discussions. Int. J. Refrig. 2011, 34, 402-415. [CrossRef]

5. Xu, S.; Fan, X.; Ma, G. Experimental investigation on heating performance of gas-injected scroll compressor using R32, R1234yf and their 20wt\%/80wt\% mixture under low ambient temperature. Int. J. Refrig. 2017, 75, 286-292. [CrossRef]

6. Qi, H.; Liu, F.; Yu, J. Performance analysis of a novel hybrid vapor injection cycle with subcooler and flash tank for air-source heat pumps. Int. J. Refrig. 2017, 74, 540-549. [CrossRef]

7. Tello-Oquendo, F.M.; Navarro-Perris, E.; Gonzalvez-Macia, J. A comprehensive study of two-stage vapor compression cycles with vapor-injection for heating applications, taking into account heat sink of finite capacity. Int. J. Refrig. 2018, 93, 52-64. [CrossRef]

8. Xu, S.; Niu, J.; Cui, Z.; Ma, G. Experimental research on vapor-injectetd heat pump using injection subcooling. Appl. Therm. Eng. 2018, 136, 674-681. [CrossRef]

9. Zhao, Y.; Li, Z.; Zhang, X.; Wang, X.; Dong, X.; Gao, B.; Gong, M.; Shen, J. Azeotropic refrigerants and its application in vapor compression refrigeration cycle. Int. J. Refrig. 2019, 108, 1-13. [CrossRef]

10. Mohammad, T.; Hoseyn, S. Optimal design of a two-stage refrigeration cycle for natural gas pre-cooling in a gas refinery considering the best allocation of refrigerant. Energy Convers. Manage. 2020, 210, 112743.

11. D'Angelo, J.V.H.; Aute, V.; Radermacher, R. Performance evaluation of a vapor injection refrigeration system using mixture refrigerant R290/R600a. Int. J. Refrig. 2016, 65, 194-208. [CrossRef]

12. Lee, Y.; Kang, D.; Jung, D. Performance of virtually non-flammable azeotropic HFO1234yf/HFC134a mixture for HFC134a applications. Int. J. Refrig. 2013, 36, 1203-1207. [CrossRef]

13. Shaik, S.V.; Babu, T.P.A. Theoretical performance investigation of vapour compression refrigeration system using HFC and HC refrigerant mixtures as alternatives to replace R22. Energy Procedia 2017, 109, $235-242$. [CrossRef]

14. Chen, J.; Havtun, H.; Palm, B. Screening of working fluids for the ejector refrigeration system. Int. J. Refrig. 2014, 47, 1-14. [CrossRef] 
15. Besagni, G.; Mereu, R.; Leo, G.D.; Inzoli, F. A study of working fluids for heat driven ejector refrigeration using lumped parameter models. Int. J. Refrig. 2015, 58, 154-171. [CrossRef]

16. Calm, J.M. The next generation of refrigerants-Historical review, considerations, and outlook. Int. J. Refrig. 2008, 31, 1123-1133. [CrossRef]

17. Gil, B.; Kasperski, J. Efficiency analysis of alternative refrigerants for ejector cooling cycles. Energy Convers. Manage. 2015, 94, 12-18. [CrossRef]

18. Molés, F.; Navarro-Esbrí, J.; Peris, B.; Mota-Babiloni, A.; Kontomaris, K. Thermodynamic analysis of a combined organic Rankine cycle and vapor compression cycle system activated with low temperature heat sources using low GWP fluids. Appl. Therm. Eng. 2015, 87, 444-453. [CrossRef]

19. Sethi, A.; Becerra, E.V.; Motta, S.Y. Low GWP R134a replacements for small refrigeration (plug-in) applications. Int. J. Refrig. 2016, 66, 64-72. [CrossRef]

20. Intergovernmental Panel on Climate Change (IPCC). Fifth Assessment Report: Climate Change; IPCC: Geneva, Switzerland, 2013.

21. Calm, J.M.; Hourahan, G.C. Physical, safety, and environmental data summary for current and alternative refrigerants. In Proceedings of the 23rd International Congress of Refrigeration, Prague, Czech Republic, 21-26 August 2011; pp. 1-22.

22. Saleh, B.; Weingerl, U.; Wendland, M. Description of the Thermodynamic Properties of Natural Refrigerants with BACKONE Equations. In Proceedings of the IIR Conference on Thermophysical Properties and Transfer Processes of New Refrigerants, Paderborn, Germany, 3-5 October 2001; pp. 31-38.

23. Saleh, B.; Wendland, M. Screening of pure fluids as alternative refrigerants. Int. J. Refrig. 2006, 29, $260-269$. [CrossRef]

24. Saleh, B.; Koglbauer, G.; Wendland, M.; Fischer, J. Working fluids for low temperature organic Rankine cycles. Energy 2007, 32, 1210-1221. [CrossRef]

25. Lai, N.A.; Wendland, M.; Fischer, J. Working fluids for high-temperature organic Rankine cycles. Energy 2011, 36, 199-211. [CrossRef]

26. Saleh, B. Performance analysis and working fluid selection for ejector refrigeration cycle. Appl. Therm. Eng. 2016, 107, 114-124. [CrossRef]

27. Saleh, B.; Wendland, M. Description of the Thermodynamic Properties of Fluorinate Ethers as Pure and Mixed Refrigerants with BACKONE equations, abstract no. In Proceedings of the 17th IUPAC Conference on Chemical Thermodynamics, Rostock, Germany, 28 July-2 August 2002.

28. Saleh, B.; Wendland, M. Screening of mixture as alternative refrigerants. In Proceedings of the Eurotherm Seminar No. 72 on Thermodynamics, Heat and Mass Transfer of Refrigeration Machines and Heat Pumps, Valencia, Spain, 31 March-2 April 2003; pp. 331-336.

29. Lai, N.A.; Phan, T.T.H. Review of the BACKONE equation of state and its applications. Mol. Phys. 2017, 115, 1041-1050. [CrossRef]

30. Bolaji, B.O.; Komolafe, D.O.; Ajayi, F.O.; Akinnibosun, E. Performance Assessment of Three Eco-Friendly Hydro-Fluorocarbon and Hydrocarbon Refrigerant Mixtures as R22 Alternatives in Refrigeration Systems. Middle East. J. Sci. Res. 2015, 23, 1677-1684.

31. Bolaji, B.O.; Oyelaran, O.A.; Okoye, O.C. Thermodynamic study of environment-friendly R429A, R435A and R457A refrigerants as substitutes for ozone depleting R22 in refrigeration and air-conditioning systems. Sci. J. Marit. Res. 2017, 31, 45-52.

(C) 2020 by the authors. Licensee MDPI, Basel, Switzerland. This article is an open access article distributed under the terms and conditions of the Creative Commons Attribution (CC BY) license (http://creativecommons.org/licenses/by/4.0/). 